Research paper

\title{
Hydroalcoholic extract of Sargassum Oligocystum attenuates pentylenetetrazole-induced seizures by potentiating antioxidant activity in mice
}

\author{
Ali Movahed ${ }^{\mathrm{a}}$, Mahbubeh Ghaderi ${ }^{\mathrm{b}}$, Adel Daneshi ${ }^{\mathrm{c}}$, Iraj Nabipour ${ }^{\mathrm{c}}$, \\ Mojtaba Keshavarz ${ }^{\mathrm{d}, \mathrm{e}, *}$ \\ a Department of Biochemistry, Bushehr University of Medical Sciences, Bushehr, Iran \\ b School of Medicine, Bushehr University of Medical Sciences, Bushehr, Iran \\ ${ }^{\mathrm{c}}$ Department of Marine Toxicology, The Persian Gulf Marine Biotechnology Research Center, Bushehr University of Medical Sciences, Bushehr, Iran \\ d Department of Pharmacology, Bushehr University of Medical Sciences, Bushehr, Iran \\ e Shiraz Neuroscience Research Center, Shiraz University of Medical Sciences, Shiraz, Iran
}

\section{A R T I C L E I N F O}

\section{Article history:}

Received 21 January 2017

Accepted 15 May 2017

Available online 17 May 2017

\section{Keywords:}

Mice

Oxidative stress

Pentylenetetrazole

Sargassum oligocystum

Seizure

\begin{abstract}
A B S T R A C T
Objectives: The aim of this study was to investigate the potential effects of Sargassum oligocystum extract on the pentylenetetrazole (PTZ) seizure and the contribution of antioxidant capacity of this alga to its antiepileptic effect.

Methods: A dose of $100 \mathrm{mg} / \mathrm{kg}$ PTZ was used to induce the seizure in the male albino mice. Extract of Sargassum oligocystum in four doses $(100,200,400$ and $600 \mathrm{mg} / \mathrm{kg})$, diazepam $(5 \mathrm{mg} / \mathrm{kg})$ and the vehicle were used $30 \mathrm{~min}$ before the injection of PTZ $(n=8)$. The onsets of clonic and tonic-clonic seizures, as well as the latency of death of animals, were recorded and the total antioxidant capacity (TAC), Superoxide dismutase (SOD) activity and catalase level were measured. Data were analyzed using one-way ANOVA or Kruskal-Wallis tests.

Results: Sargassum oligocystum extract at the doses of 400 and $600 \mathrm{mg} / \mathrm{kg}$ significantly increased the latency of clonic and tonic-clonic seizures. Also, at the doses of 100,200 and $400 \mathrm{mg} / \mathrm{kg}$ significantly increased the TAC. Moreover, Sargassum oligocystum at the doses of 200 and $400 \mathrm{mg} / \mathrm{kg}$ increased the SOD activity and at the doses of 400 and $600 \mathrm{mg} / \mathrm{kg}$ increased the catalase level in neural cells compared with the vehicle-treated group.

Conclusion: Sargassum oligocystum extract inhibited PTZ-induced seizure. Attenuation of oxidative stress may partly be responsible for the anticonvulsant effects of this alga in the PTZ-induced seizures. Therefore, marine algae, especially Sargassum oligocystum, may be a valuable target to discover new antiepileptic drugs.
\end{abstract}

(c) 2017 Indian Epilepsy Society. Published by Elsevier, a division of RELX India, Pvt. Ltd. All rights reserved.

\section{Introduction}

Epilepsy is one of the most prevalent neurological disorder around the world. 1 It has been estimated that 5.8 per 1000 population in developed countries and about 12.8 per 1000 in lower income countries suffer from this disorder.2 Pharmacotherapy is the primary method for controlling epileptic seizure. However, about $30 \%$ of patients suffer from refractory epilepsy or are unable to tolerate the adverse effects of antiepileptic drugs.3,4 Thus, it is of

\footnotetext{
* Corresponding author at: Shiraz Neuroscience Research Center, Chamran Hospital, Chamran Boulevard, Shiraz, Iran.

E-mail address: moj.ph60@yahoo.com (M. Keshavarz).
}

great importance to find new drugs with increased safety and efficacy profile.

The exact pathophysiology of epileptic seizure needs to be fully elucidated, though the imbalance between the excitatory and inhibitory neurotransmission in the central nervous system (CNS) may play important roles in this disorder.5,6 Furthermore, increased oxidative stress have a great contribution to the pathophysiology of epilepsy.7 Several animal models including the amygdala kindling, 8 kainic acid,9 PTZ kindling,10 and acute PTZ-induced seizures11 have confirmed the involvement of enhanced oxidative stress in experimental epilepsy. Successful administration of the antioxidants in various models of epilepsy may be another proof for the association of oxidative stress with epileptic seizure.12,13 
Currently, phytomedicines are widely used for the management of epilepsy in many parts of the world 14 and there is growing interest in using natural products as an alternative source for antiepileptic drugs.15,16 Marine algae have several biological activities, nutritional benefits, and medicinal potential 17 with confirmed antioxidant18 and anti-inflammatory 19 activities. Thus, phytomedicine like marine algae may be favorite targets for developing new antiepileptic drugs. 20

Sargassaceae family is brown algae which are widely distributed in the tropical and subtropical oceans in the world.21 Sargassum oligocystum (S. oligocyctum) is a member of Sargassaceae family that is widely spread over the coastal waters of Persian Gulf.22 There are many in vitro and in vivo studies about the antioxidant capacity of Sargassum species in the peripheral tissues.23,24 With regards to the antioxidant activity of S. oligocyctum 25 and the role of oxidative stress in the pathophysiology of the epileptic seizure, the study was designed to assess the potential effects of S. oligocyctum extract on the pentylenetetrazole(PTZ) seizure and the contribution of antioxidant activity of this alga to its antiepileptic effect.

\section{Materials and methods}

\subsection{Alga materials and preparation of hydroalcoholic extract}

We collected S. oligocyctum from the coastal waters of Bushehr (southwest of Iran) in May 2016. They were thoroughly washed with double distilled water to remove impurities, dried in the ambient temperature and finally ground into fine powder. Then; it was soaked in ethanol (70\%) at a ratio of $1: 10$. The mixture was homogenized for $72 \mathrm{~h}$ on a shaker. The supernatant was filtered using Whatman paper No. 1 and centrifuged at $4000 \mathrm{rpm}, 4{ }^{\circ} \mathrm{C}$ for $10 \mathrm{~min}$. The solvent was separated using the rotary evaporator, and the extract was kept in the refrigerator $\left(4^{\circ} \mathrm{C}\right)$ until use.

\subsection{Study design}

Male albino Swiss strain of mice was obtained from Razi Institute (Tehran, Iran). We kept animals in the Plexiglas cages ( 5 animals per each cage) on a regular dark/light cycles $(12 \mathrm{~h} / 12 \mathrm{~h})$, controlled temperature $\left(22 \pm 2{ }^{\circ} \mathrm{C}\right)$ and free access to food and water. Forty-eight mice were randomly allocated to the 6 separate groups $(n=8)$. We used S. oligocyctum extract in four different doses $(100,200,400$ and $600 \mathrm{mg} / \mathrm{kg}$ ), diazepam ( $5 \mathrm{mg} / \mathrm{kg}$ as a standard antiepileptic drug that is used in PTZ model), and the vehicle (normal saline) $30 \mathrm{~min}$ before the PTZ injection. The experiment was approved by the local Animal Ethics Committee, which follows the European Communities Council to minimize the number and suffering of animals.

\subsection{Seizures induced by PTZ}

PTZ at a dose of $100 \mathrm{mg} / \mathrm{kg}$ was used for the induction of clonic and tonic-clonic seizures in mice. After injection of PTZ, animals were moved into separate cages and monitored for $30 \mathrm{~min}$. The clonic seizure was defined as an over 3 second's clonus of the animal body which was accompanied by the loss of righting reflex. 26 Generalized clonus of animal body with the extension of both forelimbs and hind limb was defined as the generalized tonicclonic seizure. We recorded the latency of the clonic and generalized tonic-clonic seizures. Finally, the latency of death of animals after injection of PTZ and the number of animals protected from PTZ-induced seizure and death were recorded.
2.4. Brain tissue homogenate preparation and the measurement of anti-oxidative parameters

Thirty minutes after the injection of PTZ, the mice were sacrificed by neck dislocation. Then, the whole brain was removed, washed and stored in the phosphate buffer saline (PBS) $(\mathrm{pH}=7.4)$ at $-20^{\circ} \mathrm{C}$. On the day of the experiment, the whole brain was washed again, twice with cold PBS. The tissues were homogenized using tris aminomethane buffer $(0.1 \mathrm{M}, \mathrm{pH}=7.4)$, triton $\mathrm{X}-100$ $(0.5 \%)$ and mercaptoethanol $(\mathrm{ME})(5 \mathrm{mM})$ at $4{ }^{\circ} \mathrm{C}$. The homogenate was centrifuged at $14000 \mathrm{~g}, 4^{\circ} \mathrm{C}$ for $5 \mathrm{~min}$ and the supernatant was used to measure the antioxidant capacity and enzymes. The total antioxidant capacity (TAC), superoxide dismutase (SOD) activity and catalase level were measured using commercial kits (Biovision, USA).

\subsection{Statistical analysis}

The Kolmogorov-Smirnov test was used to check the normal distribution of variables. We reported median and inter quartile range 25 (IQR25) for non-normal distributed variables and the mean \pm standard error of the mean (SEM) for other variables. We used Kruskal-Wallis test followed by the Dunn's test to analyze the clonic, tonic-clonic seizure and latency for death, mainly because of deviation from the normal distribution of these variables. Furthermore, we used one-way ANOVA followed by an LSD test for pairwise comparison of TAC, SOD and catalase data. We considered the $p$-value of lower than 0.05 as the significant level. All the analyses were carried out with SPSS software version 23 .

\section{Results}

\subsection{Effects of S. oligocystom extract on the onset of PTZ-induced clonic and tonic-clonic seizures}

The Kruskal-Wallis analysis showed a significant difference between various treatment groups $\left(X^{2}(5)=28.47, p=0.000\right)$ (Table 1). Diazepam increased the onset of PTZ-induced clonic seizure compared with the vehicle-treated group (Table 1). Moreover, S. oligocyctum extract at the doses of 400 and $600 \mathrm{mg} / \mathrm{kg}$ had a higher latency of the clonic seizure compared with the vehicle-treated group (Table 1 ). However, S. oligocyctum (100 and $200 \mathrm{mg} / \mathrm{kg}$ ) had no effect on the onset of clonic seizure in mice (Table 1). Our study showed that $37.5 \%$ of animals treated with diazepam and $12.5 \%$ treated with S. oligocyctum $(600 \mathrm{mg} / \mathrm{kg})$ were protected from PTZ-induced clonic seizure. Other treatments including S. oligocyctum $(100,200$ and $400 \mathrm{mg} / \mathrm{kg})$, and the vehicle did not protect animals against PTZ-induced clonic seizure.

Table 1

The effects of Sargassum oligocystum extracts and diazepam on the pentylenetetrazole-induced clonic seizure in mice.

\begin{tabular}{llll}
\hline Treatment & Median (IQR25) & Statistic & p value \\
\hline S. oligocyctum $600 \mathrm{mg} / \mathrm{kg}$ & $97.5(69.25)$ & 19.00 & 0.046 \\
S. oligocyctum $400 \mathrm{mg} / \mathrm{kg}$ & $124.00(86.25)$ & 23.16 & 0.007 \\
S. oligocyctum $200 \mathrm{mg} / \mathrm{kg}$ & $91.00(64.25)$ & 15.19 & 0.270 \\
S. oligocyctum $100 \mathrm{mg} / \mathrm{kg}$ & $67.50(58.25)$ & 8.34 & 1.000 \\
Diazepam & $282.00(235.00)$ & 34.78 & 0.000 \\
Vehicle-treated & $54.5(43)$ & - & - \\
\hline
\end{tabular}

Drugs were administered interaperitoneally $30 \mathrm{~min}$ before the injection of pentylenetetrazole. Data presented as median and IQR 25 (Inter Quartile Range 25) and analyzed using the Kruskal-Wallis test followed by the Dunn's test. Each group consisted of 8 animals. * p value $<0.05$ was considered as significant level, sar: Sargassum. 
Table 2

The effects of Sargassum oligocystum extracts on the pentylenetetrazole-induced tonic-clonic seizure in mice.

\begin{tabular}{llll}
\hline Treatment & Median (IQR25) & Statistic & p value \\
\hline S. oligocyctum $600 \mathrm{mg} / \mathrm{kg}$ & $220.00(90.00)$ & 16.65 & 0.034 \\
S. oligocyctum $400 \mathrm{mg} / \mathrm{kg}$ & $268.50(136.75)$ & 20.60 & 0.004 \\
S. oligocyctum $200 \mathrm{mg} / \mathrm{kg}$ & $128.50(86.00)$ & 11.75 & 0.380 \\
S. oligocyctum $100 \mathrm{mg} / \mathrm{kg}$ & $128.50(86.00)$ & 5.94 & 1.000 \\
Vehicle-treated & $54.5(43)$ & - & - \\
\hline
\end{tabular}

Drugs were administered interaperitoneally $30 \mathrm{~min}$ before the injection of pentylenetetrazole. Data presented as median and IQR 25 (Inter Quartile Range 25) and analyzed using the Kruskal-Wallis test followed by the Dunn's test. Each group consisted of 8 animals. ${ }^{*}$ p value $<0.05$ was considered as significant level, sar: Sargassum.

\section{Table 3}

The effects of Sargassum oligocystum extracts on the pentylenetetrazole-induced mortality in mice.

\begin{tabular}{llll}
\hline Treatment & Median (IQR25) & Statistic & p value \\
\hline S. oligocyctum $600 \mathrm{mg} / \mathrm{kg}$ & $627.50(265.25)$ & 15.12 & 0.040 \\
S. oligocyctum $400 \mathrm{mg} / \mathrm{kg}$ & $641.00(283.00)$ & 15.87 & 0.024 \\
S. oligocyctum $200 \mathrm{mg} / \mathrm{kg}$ & $580.00(252.50)$ & 14.88 & 0.023 \\
S. oligocyctum $100 \mathrm{mg} / \mathrm{kg}$ & $280.00(155.00)$ & 9.16 & 0.471 \\
Vehicle-treated & $112.50(10.3 .50)$ & - & - \\
\hline
\end{tabular}

Drugs were administered interaperitoneally $30 \mathrm{~min}$ before the injection of pentylenetetrazole. Data presented as median and IQR 25 (Inter Quartile Range $25)$ and analyzed using the Kruskal-Wallis test followed by the Dunn's test. Each group consisted of 8 animals. * P value $<0.05$ was considered as significant level, sar: Sargassum.
Diazepam completely protected animals against PTZ-induced tonic-clonic seizure. Moreover, 25\% of animals treated with $S$. oligocyctum $(400 \mathrm{mg} / \mathrm{kg}$ ) and $12.5 \%$ treated with S. oligocyctum (600 and $100 \mathrm{mg} / \mathrm{kg}$ ) did not experience the tonic-clonic seizure. Furthermore, the latency of tonic-clonic seizure was significantly different between various treatment groups $\left(X^{2}(4)=17.29\right.$, $\mathrm{p}=0.002$ ) (Table 2). Post HOC analysis showed that $S$. oligocyctum (400 and $600 \mathrm{mg} / \mathrm{kg}$ ) increased the latency of the tonic-clonic seizure induced by PTZ compared with the vehicle-treated group (Table 2). However, S. oligocyctum (100 and $200 \mathrm{mg} / \mathrm{kg}$ ) had no effect on the tonic-clonic seizure compared with the vehicletreated group (Table 2).

\subsection{Effects of S. oligocystom extract on the PTZ-induced mortality in mice}

All the animals treated with diazepam, $50 \%$ of the animals treated with S. oligocyctum (400 and $600 \mathrm{mg} / \mathrm{kg}$ ), $37.5 \%$ of the animals treated with S. oligocyctum $(200 \mathrm{mg} / \mathrm{kg})$ and $12.5 \%$ of the animals treated with $S$. oligocyctum $(100 \mathrm{mg} / \mathrm{kg})$ were protected against PTZ-induced mortality. Moreover, the latency of death among animals treated with various treatments was significantly different $\left(\mathrm{X}^{2}(4)=17.09, \mathrm{p}=0.002\right)$. Post HOC analysis showed that $S$. oligocyctum at the doses of 200,400 and $600 \mathrm{mg} / \mathrm{kg}$ had a higher latency for death after challenging with PTZ (Table 3). However, S. Oligocyctum at the dose of $100 \mathrm{mg} / \mathrm{kg}$ had no effect on the latency for death (Table 3 ).

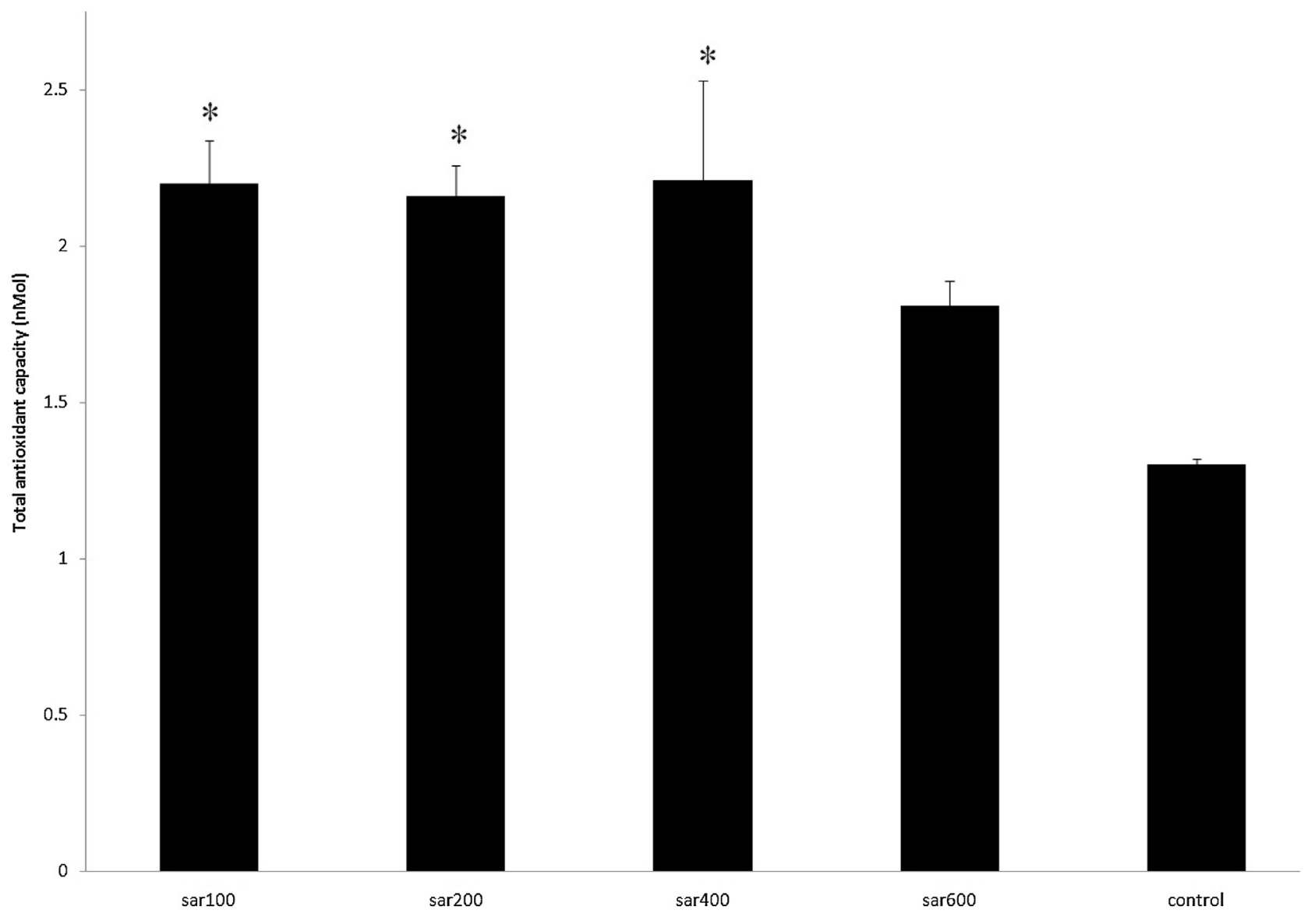

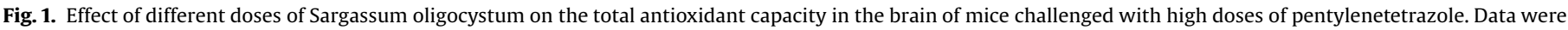

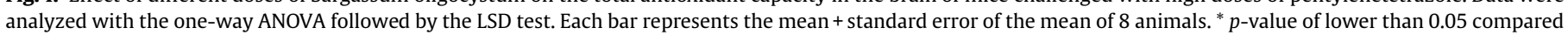
with the vehicle-treated group. Sar: sargassum oligocystum. 


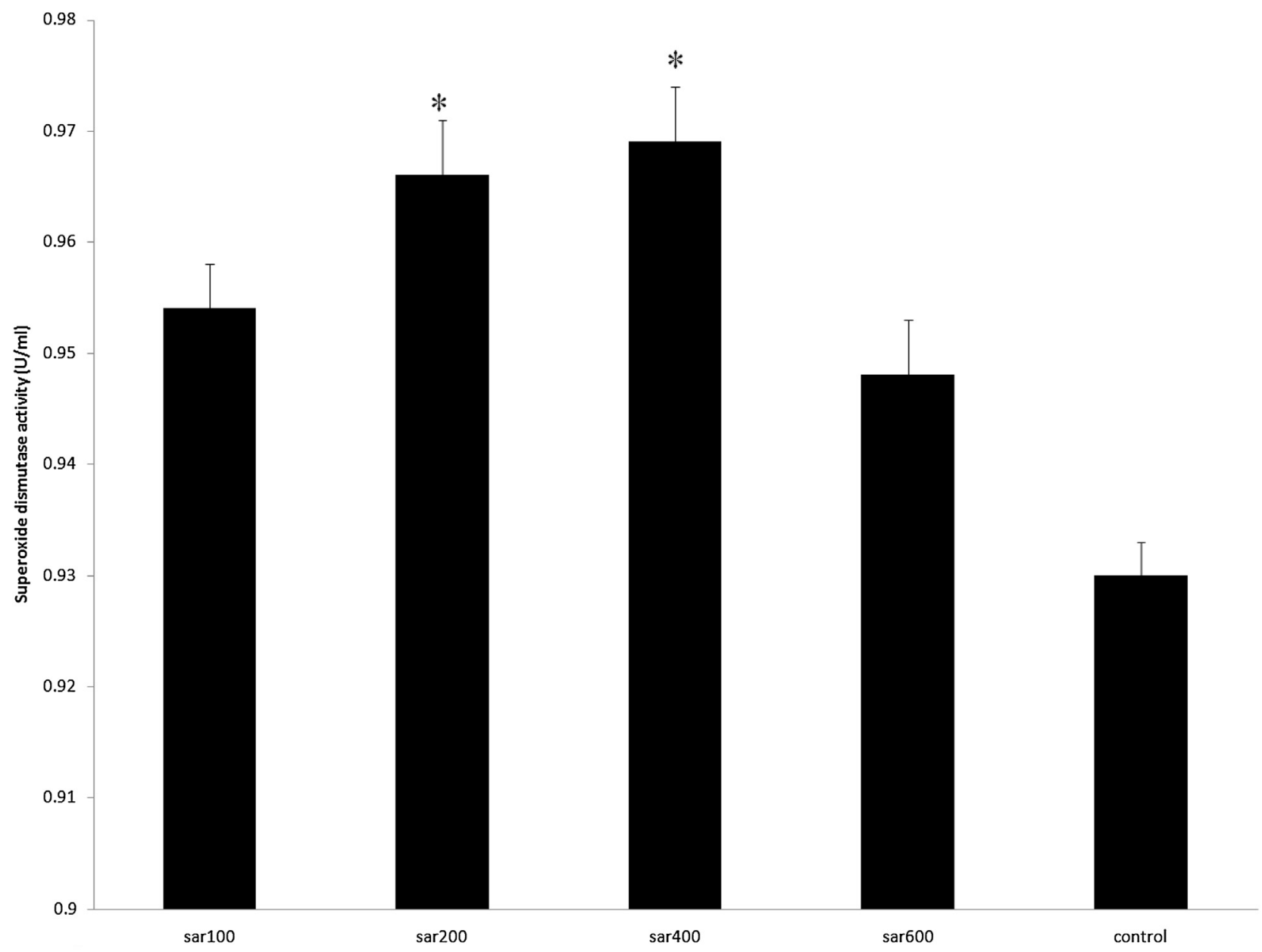

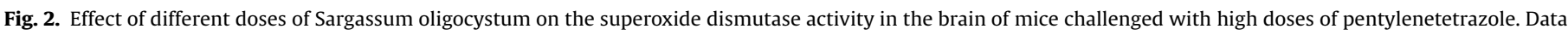

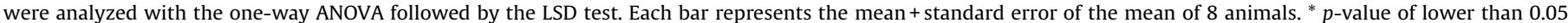
compared with the vehicle-treated group. Sar: sargassum oligocystum.

\subsection{Effects of S. oligocyctum on the TAC and antioxidant enzymes}

Our study showed that the TAC content of the neural cells was significantly different among the treatment groups $(F(4)=8.94$, $\mathrm{p}=0.000)$. S. oligocyctum at the doses of $100 \mathrm{mg} / \mathrm{kg}(0.000)$, $200 \mathrm{mg} / \mathrm{kg}(0.000)$ and $400 \mathrm{mg} / \mathrm{kg}(0.000)$ significantly increased the TAC content of neural cells compared with the vehicle-treated group (Fig. 1). However, S. oligocyctum $(600 \mathrm{mg} / \mathrm{kg}$ ) had no effect on the TAC level of neural cells (Fig. 1).

Furthermore, a significant difference was observed in the neural SOD activity among treatment groups $(F(4)=7.36, p=0.000)$. Post HOC analysis showed that $S$. oligocyctum at the doses of 200 and $400 \mathrm{mg} / \mathrm{kg}$ had significantly higher SOD activity compared with the vehicle-treated group $(\mathrm{p}=0.001$ and $\mathrm{p}=0.000$, respectively) (Fig. 2). However, S. oligocyctum at the doses of 100 and $600 \mathrm{mg} /$ $\mathrm{kg}$ had no effect on the SOD activity in the neural cells ( $\mathrm{p}=0.071$ and $\mathrm{p}=0.316$, respectively) (Fig. 2).

The catalase level of neural cells was significantly different between various treatment groups $(F(4)=3.28, p=0.024)$. $S$. oligocyctum at the doses of 400 and $600 \mathrm{mg} / \mathrm{kg}$ significantly increased the catalase level of neural cells compared with the vehicle-treated group ( $\mathrm{p}=0.034$ and 0.021 , respectively) (Fig. 3). However, S. oligocyctum at the doses of 100 and $200 \mathrm{mg} / \mathrm{kg}$ had no effect on the catalase level compared with the vehicle-treated group ( $\mathrm{p}=0.369$ and $\mathrm{p}=0.121$, respectively) (Fig. 3 ).

\section{Discussion}

S. oligocyctum is a macroalga that is widely distributed in the coastal area of the Persian Gulf. Previous reports have shown antibacterial and anticancer effects of this marine alga.22,27 Our study also showed that $S$. oligocyctum extract can attenuate PTZinduced seizure in mice. There is very limited information about the antiepileptic effects of marine algae and a few reports about the anticonvulsant effects of sargassaceae family algae. However, fucosterol, a steroid derived from S. fusiforme, possessed anticonvulsant effects against electroshock seizures.28 Therefore, the sargassaceae family may be an important potential target for developing new antiepileptic drugs. In contrast, ethanol and chloroform extracts of Adina tetrastromatica, a brown macroalga, had no effect on the latency of PTZ-induced clonic seizure.29

Numerous reports have shown the role of oxidative stress in the development of various disorders, including cancer, neurodegenerative disorders, atherosclerosis and epilepsy.7,30 Moreover, oxidative stress induced damage may be involved in the pathophysiological changes, following acute neurological insults like seizures.8,31 Animal and human studies have shown that oxidative stress markers have increased in the epileptic subjects. 32-36 Epileptogenesis in the brain impair the oxidative stress balance by reducing the antioxidant defense and increasing free radicals. 37 The enhanced oxidative stress in the brain may be 


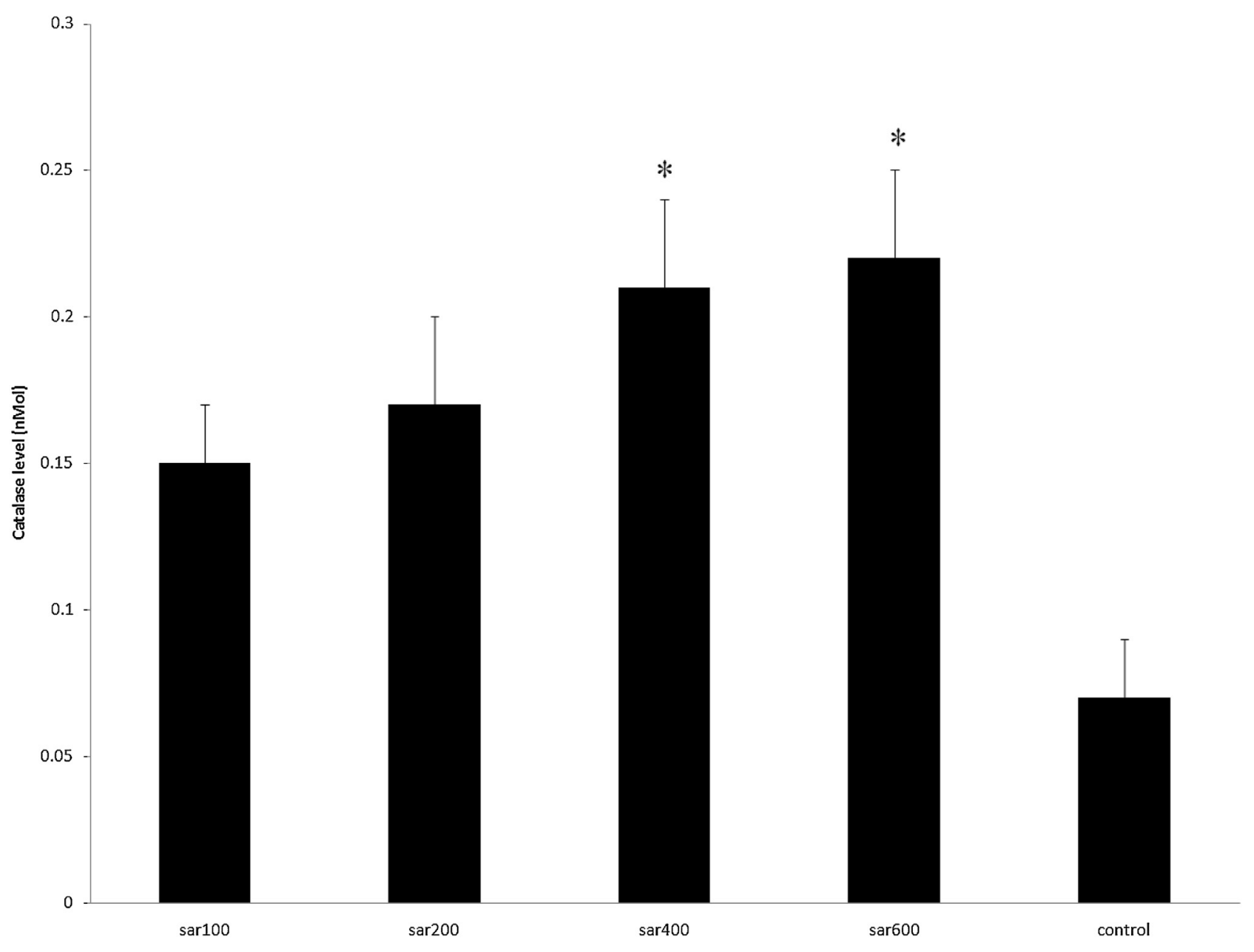

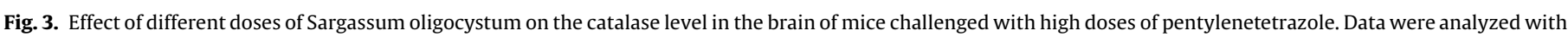

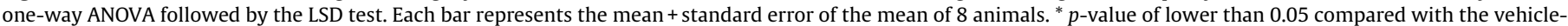
treated group. Sar: sargassum oligocystum.

correlated with decreased amount of inhibitory neurotransmitters like GABA and the initiation of convulsion in the cerebral cortex of animals.38 Furthermore, increased activity of catalase in the hippocampus has protected animals against epileptic seizure.39 Our study showed that S. oligocyctum extract enhanced antioxidant content of the animal brains when challenged with high doses of PTZ. However, only the catalase activity was matched with the anticonvulsant effects of S. oligocyctum. In accord with our study, Cárdenas-Rodríguez et al. showed that tilia, a medicinal plant, inhibited PTZ-induced seizure mainly by modulating oxidative stress in the animal brains. 40

The results of our study showed that decreasing oxidative stress by the $S$. oligocyctum extract may attenuate PTZ-induced seizure, but may not be able to completely block it. There are many reports about the anticonvulsant activity of medicinal plants with antioxidant effects.41-43 In contrast, there is some inconsistency about the anticonvulsant effects of antioxidant agents. 44 Trolox, a vitamin E analog, increased the latency of clonic seizure in pilocarpine and ferrous chloride 39 but had no effect in the PTZ, maximal electroshock and kainic acid models.45,46 Accordingly, the attenuation of oxidative stress may be partly responsible for the inhibition of PTZ-induced seizures by the S. oligocyctum extract.

PTZ is a convulsant agents that acts via the blockade of GABAA receptor.47,48 Moreover, PTZ induced seizures are accompanied with decreased indigenous antioxidants and increased oxidative stress parameters in the mouse cerebral cortex.49 In this regard, it has been shown that a single dose of PTZ altered $\mathrm{GABA}_{\mathrm{A}}$ receptor density and function 48 and whole brain free radicals, 50 reduced total SOD activity and $\alpha$-tocopherol content in rat brain. 51 Therefore, the convulsant effects of PTZ may contribute to the GABAA and oxidative stress modulation in the animal models of epilepsy. Our study showed that $S$. oligocyctum extract diminished PTZ-induced seizure and increased antioxidant capacity in the mouse brain. It is probable to assume that this alga may modulate $\mathrm{GABA}_{\mathrm{A}}$ and brain antioxidant capacity to inhibit PTZ-induced seizure in the mice. Although, the attenuating of oxidative stress may mediate, at least in part, the anticonvulsant effects of $S$. oligocyctum extract, there are other possibilities about the mechanism of action of this alga.

In this study, the hydroalcoholic extract of S. oligocyctum was used and the active compounds that are responsible for the anticonvulsant effects of the algae are not known. Tannins, saponins, alkaloids, sterols, flavonoids and triterpenes are the most abundant compounds in the S. oligocyctum (Table 4).25,52 Among these compounds, flavonoids and sterols are substances with intense antioxidant activity.28,53 Thus, these substances may be the most important compounds responsible for the anticonvulsant effects of S. oligocyctum. Flavonoids are also structurally similar to benzodiazepine and produce an antiepileptic effect, possibly by modulation of $\mathrm{GABA}_{\mathrm{A}}$ receptors.54 In this regard, it has been shown that allosteric modulation of benzodiazepine site of $\mathrm{GABA}_{\mathrm{A}}$ receptors may be responsible for some of central effects of herbal flavonoids.55 It is noteworthy that the interaction of flavonoids with GABA receptor and its relevance to the epilepsy 
Table 4

Chemical structure of possible active compounds of Sargassum oligocystum extract.

\begin{tabular}{|c|c|}
\hline Compound & Chemical structure \\
\hline Tannins & \\
\hline Saponins & \\
\hline Sterols & \\
\hline Flavonoids & \\
\hline Triterpenes & \\
\hline
\end{tabular}

management should be confirmed in the future studies. Furthermore, fucosterol, a sterol, inhibited seizures produced by maximal electroshock in animals.28 Currently, it is not possible to show that the modulation of oxidative stress and the direct effect of compounds like flavonoids or sterols may be responsible for the anticonvulsant effects of $S$. oligocyctum. However, it can be proposed that the anticonvulsant effect of $S$. oligocyctum may be the sum of oxidative stress modulation and direct effects of active compounds of this alga. Further research may be warranted to clarify the exact mechanisms responsible for the anticonvulsant activity of $S$. oligocyctum.

The main limitation of this study was using the hydroalcoholic extract of S. oligocyctum. However, this extract was used to screen for potential anticonvulsant effects of this alga. It is suggested to use specific fractions and components of this alga in different animal models in the future studies. Furthermore, it is necessary to clarify the exact mechanism(s) responsible for the anticonvulsant effect of this alga.

\section{Conclusion}

S. oligocyctum extract inhibited PTZ-induced seizure and enhanced TAC, SOD and catalase levels in the mouse brain. The attenuation of oxidative stress may be, at least partly, responsible for the anticonvulsant effects of S. oligocyctum in the PTZ-induced seizures. Therefore, our study suggests that marine algae especially, S. oligocyctum may be a potential target to discover new antiepileptic drugs. Although, some studies did not show any adverse effect after using sargassum extracts, it is important to determine detailed profile of side effects of this alga before using in human studies.

\section{Conflict of interest}

The authors have none to declare.

\section{Author's contribution}

Ali Movahed: the design of the study, acquisition of data, analysis of data, revising the manuscript and final approval of the manuscript.

Mahbobeh Ghaderi: acquisition of data, drafting the manuscript and final approval of the manuscript.

Adel Daneshi: acquisition of data, drafting the manuscript and final approval of the manuscript.

Iraj Nabipour: the design of the study, analysis of data, revising the manuscript and final approval of the manuscript. 
Mojtaba Keshavarz: the design of the study, analysis and interpretation of data, drafting and revising the article and final approval of the manuscript.

\section{Acknowledgements}

We like to appreciate Mrs. Hajian helping during the performance of this study. We also thank Miss Khadijeh Hosseini for her cooperation during the study. We should be grateful to the deputy for research of Bushehr University of Medical Sciences for providing financial support for the present study. However, the funding source had no role in the study design, data collection, analysis, and interpretation.

\section{References}

1. Leonardi M, Ustun TB. The global burden of epilepsy. Epilepsia. 2002;43 (s6):21-25.

2. Ngugi AK, Bottomley C, Kleinschmidt I, Sander JW, Newton CR. Estimation of the burden of active and life-time epilepsy: a meta-analytic approach. Epilepsia. 2010;51(5):883-890.

3. Kwan P, Schachter SC, Brodie MJ. Drug-resistant epilepsy. $N$ Engl J Med. 2011;365(10):919-926.

4. Perucca P, Gilliam FG. Adverse effects of antiepileptic drugs. Lancet Neurol 2012;11(9):792-802.

5. Staley K. Molecular mechanisms of epilepsy. Nat Neurosci. 2015;18(3):367372.

6. Raza M, Blair RE, Sombati S, Carter DS, Deshpande LS, DeLorenzo RJ. Evidence that injury-induced changes in hippocampal neuronal calcium dynamics during epileptogenesis cause acquired epilepsy. Proc Natl Acad Sci USA. 2004;101(50):17522-17527.

7. Chang S-J, Yu B-C. Mitochondrial matters of the brain: mitochondrial dysfunction and oxidative status in epilepsy. J Bioenerg Biomembr. 2010;42 (6):457-459.

8. Frantseva M, Velazquez JP, Tsoraklidis G, et al. Oxidative stress is involved in seizure-induced neurodegeneration in the kindling model of epilepsy. Neuroscience. 2000;97(3):431-435.

9. Gluck MR, Jayatilleke E, Shaw S, Rowan AJ, Haroutunian V. CNS oxidative stress associated with the kainic acid rodent model of experimental epilepsy. Epilepsy Res. 2000;39(1):63-71.

10. Patsoukis N, Zervoudakis G, Panagopoulos NT, Georgiou CD, Angelatou F, Matsokis NA. Thiol redox state (TRS) and oxidative stress in the mouse hippocampus after pentylenetetrazol-induced epileptic seizure. Neurosci Lett. 2004:357(2):83-86.

11. Obay BD, Taşdemir E, Tümer C, Bilgin HM, Atmaca M. Dose dependent effects of ghrelin on pentylenetetrazole-induced oxidative stress in a rat seizure model. Peptides. 2008;29(3):448-455.

12. Lapin LP, Mirzaev SM, Ryzov IV, Oxenkrug GF. Anticonvulsant activity of melatonin against seizures induced by quinolinate, kainate, glutamate, NMDA, and pentylenetetrazole in mice. J Pineal Res. 1998;24(4):215-218.

13. Martinc B, Grabnar I, Vovk T. Antioxidants as a preventive treatment for epileptic process: a review of the current status. Curr Neuropharmacol. 2014;12 (6):527-550.

14. Okoye T, Akah P, Omeke C. Evaluation of the anticonvulsant and muscle relaxant effects of the methanol root bark extracts of Annona senegalensis. APJTM. 2010;3(1):25-28.

15. Nassiri-Asl M, Shariati-Rad S, Zamansoltani F. Anticonvulsive effects of intracerebroventricular administration of rutin in rats. Prog Neuropsychopharmacol Biol Psychiatry. 2008;32(4):989-993.

16. Zhu HL, Wan JB, Wang YT, et al. Medicinal compounds with antiepileptic anticonvulsant activities. Epilepsia. 2014;55(1):3-16.

17. Pangestuti R, Kim S-K. Neuroprotective effects of marine algae. Mar Drugs. 2011;9(5):803-818

18. Athiperumalsami T, Rajeswari VD, Poorna SH, Kumar V, Jesudass LL. Antioxidant activity of seagrasses and seaweeds. Bot Mar. 2010;53(3):251-257.

19. Hua K-F, Hsu H-Y, Su Y-C, et al. Study on the antiinflammatory activity of methanol extract from seagrass Zostera japonica. J Agric Food Chem. 2006;54 (2):306-311.

20. Orhan N, Orhan DD, Aslan M, Şüküroğlu M, Orhan IE. UPLC-TOF-MS analysis of Galium spurium towards its neuroprotective and anticonvulsant activities. $J$ Ethnopharmacol. 2012;141(1):220-227.

21. Itoh H, Noda H, Amano H, Zhuaug C, Mizuno T, Ito H. Antitumor activity and immunological properties of marine algal polysaccharides, especially fucoidan, prepared from Sargassum thunbergii of Phaeophyceae. Anticancer Res. 1992;13(6A):2045-2052.

22. Zandi K, Ahmadzadeh S, Tajbakhsh S, et al. Anticancer activity of Sargassum oligocystum water extract against human cancer cell lines. Eur Rev Med Pharmacol Sci. 2010;14(8):669-673.

23. Motshakeri M, Ebrahimi M, Goh YM, Matanjun P, Mohamed S. Sargassum polycystum reduces hyperglycaemia, dyslipidaemia and oxidative stress via increasing insulin sensitivity in a rat model of type 2 diabetes. J Sci Food Agric 2013;93(7):1772-1778

24. Kim J, Karadeniz F, Ahn B-N, et al. Sargassum sp. attenuates oxidative stress and suppresses lipid accumulation in vitro. J Life Sci. 2014;24(3):274-283.

25. Mehdinezhad N, Ghannadi A, Yegdaneh A. Phytochemical and biological evaluation of some Sargassum species from Persian Gulf. Res Pharm Sci. 2016;11(3):243-249.

26. Łukawski K, Czuczwar SJ. Effect of ACE inhibitors and AT1 receptor antagonists on pentylenetetrazole-induced convulsions in mice. Neurol Sci. 2015;36 (5):779-781.

27. Tajbakhsh S, Pouyan M, Zandi K, et al. In vitro study of antibacterial activity of the alga Sargassum oligocystum from the Persian Gulf. Eur Rev Med Pharmacol Sci. 2011;15(3):293-298.

28. Zhen X-H, Quan Y-C, Jiang H-Y, Wen Z-S, Qu Y-L, Fucosterol Guan L-P. A sterol extracted from Sargassum fusiforme, shows antidepressant and anticonvulsant effects. Eur J Pharmacol. 2015;768:131-138.

29. Yende SR, Harle UN, Ittadwar AM. Insignificant anticonvulsant activity of Padina tetrastromatica (Brown macroalgae) in mice. J Pharm Negative Results. 2016;7(1):33.

30. Valko M, Rhodes C, Moncol J, Izakovic M, Mazur M. Free radicals, metals and antioxidants in oxidative stress-induced cancer. Chem Biol Interact. 2006;160 (1): $1-40$.

31. Patel M, Liang LP, Roberts I, Jackson L. Enhanced hippocampal F2-isoprostane formation following kainate-induced seizures. J Neurochem. 2001;79(5):10651069.

32. Armstead W, Mirro R, Leffler C, Busija D. Cerebral superoxide anion generation during seizures in newborn pigs. J Cereb Blood Flow Metab. 1989;9(2):175-179.

33. Bruce AJ, Baudry M. Oxygen free radicals in rat limbic structures after kainateinduced seizures. Free Radic Biol Med. 1995;18(6):993-1002.

34. Eraković V, Župan G, Varljen J, Simonić A. Pentylenetetrazol-induced seizures and kindling: changes in free fatty acids, superoxide dismutase, and glutathione peroxidase activity. Neurochem Int. 2003;42(2):173-178.

35. Aguiar CCT, Almeida AB, Araújo PVP, et al. Oxidative stress and epilepsy: literature review. Oxid Med Cell Longev. 2012;2012:

36. Oliveira A, Almeida J, Freitas R, et al. Effects of levetiracetam in lipid peroxidation level, nitrite-nitrate formation and antioxidant enzymatic activity in mice brain after pilocarpine-induced seizures. Cell Mol Neurobiol. 2007;27(3):395-406.

37. Diniz TC, Silva JC, Lima-Saraiva SRGd, et al. The role of flavonoids on oxidative stress in epilepsy. Oxid Med Cell Longev. 2015;2015.

38. Nazıroğlu M. Role of selenium on calcium signaling and oxidative stressinduced molecular pathways in epilepsy. Neurochem Res. 2009;34(12):21812191.

39. Barros D, Xavier S, Barbosa C, et al. Effects of the vitamin E in catalase activities in hippocampus after status epilepticus induced by pilocarpine in Wistar rats. Neurosci Lett. 2007:416(3):227-230.

40. Cárdenas-Rodríguez N, González-Trujano ME, Aguirre-Hernández E, et al. Anticonvulsant and antioxidant effects of Tilia americana var. mexicana and flavonoids constituents in the pentylenetetrazole-induced seizures. Oxid Med Cell Longev. 2014;2014:.

41. Hsieh C-L, Tang N-Y, Chiang S-Y, Hsieh C-T, Lin J-G. Anticonvulsive and free radical scavenging actions of two herbs, Uncaria rhynchophylla (MIQ) Jack and Gastrodia elata Bl., in kainic acid-treated rats. Life Sci.1999;65(20):2071-2082.

42. Ilhan A, Gurel A, Armutcu F, Kamisli S, Iraz M. Antiepileptogenic and antioxidant effects of Nigella sativa oil against pentylenetetrazol-induced kindling in mice. Neuropharmacology. 2005;49(4):456-464.

43. Lian XY, Zhang ZZ, Stringer JL. Anticonvulsant activity of ginseng on seizures induced by chemical convulsants. Epilepsia. 2005;46(1):15-22.

44. Xu K, Stringer JL. Antioxidants and free radical scavengers do not consistently delay seizure onset in animal models of acute seizures. Epilepsy Behav. 2008;13 (1):77-82.

45. Levy SL, Burnham W, Hwang PA. An evaluation of the anticonvulsant effects of vitamin E. Epilepsy Res. 1990;6(1):12-17.

46. Levy SL, Burnham W, Bishai A, Hwang PA. The anticonvulsant effects of vitamin E: a further evaluation. Can J Neurol Sci. 1992;19(02):201-203.

47. Huang R-Q, Bell-Horner CL, Dibas MI, Covey DF, Drewe JA, Dillon GH. Pentylenetetrazole-induced inhibition of recombinant $\gamma$-aminobutyric acid type A (GABAA) receptors: mechanism and site of action.J Pharmacol Exp Ther. 2001;298(3):986-995.

48. Pagonopoulou O, Angelatou F. Time development and regional distribution of $[3 \mathrm{H}]$ nitrobenzylthioinosine adenosine uptake site binding in the mouse brain after acute pentylenetetrazol-induced seizures. J Neurosci Res. 1998;53 (4):433-442.

49. Patsoukis N, Zervoudakis G, Georgiou CD, Angelatou F, Matsokis NA Panagopoulos NT. Effect of pentylenetetrazol-induced epileptic seizure on thiol redox state in the mouse cerebral cortex. Epilepsy Res. 2004;62(1):65-74.

50. Rauca C, Zerbe R, Jantze $H$. Formation of free hydroxyl radicals after pentylenetetrazol-induced seizure and kindling. Brain Res. 1999;847 (2):347-351.

51. Rauca C, Wiswedel I, Zerbe R, Keilhoff G, Krug M. The role of superoxide dismutase and $\alpha$-tocopherol in the development of seizures and kindling induced by pentylenetetrazol-influence of the radical scavenger $\alpha$-phenyl-Ntert-butyl nitrone. Brain Res. 2004;1009(1):203-212.

52. Baleta FN, Laureta LV, Apines-Amar MJS, Padilla PIP, Quinitio GF. Biological activity of extracts of Sargassum oligocystum (Magnaye) against aquaculture pathogenic bacteria. Isr J Aquac. 2011;IIC(63):667. 
53. Zhang H, Tsao R. Dietary polyphenols, oxidative stress and antioxidant and anti-inflammatory effects. Curr Opin Food Sci. 2016;8:33-42.

54. Choudhary N, Bijjem KRV, Kalia AN. Antiepileptic potential of flavonoids fraction from the leaves of Anisomeles malabarica.J Ethnopharmacol. 2011;135 (2):238-242.
55. Avallone R, Zanoli P, Puia G, Kleinschnitz M, Schreier P, Baraldi M. Pharmacological profile of apigenin, a flavonoid isolated from Matricaria chamomilla. Biochem Pharmacol. 2000;59(11):1387-1394. 